\title{
2 Procedural fairness and jury satisfaction
}

\section{An analysis of relational dimensions}

\author{
Jane Goodman-Delahunty, David Tait, \\ and Natalie Martschuk
}

\subsection{Introduction}

Challenges faced by juries in performing their duties are well documented. These include the unfamiliarity and gravity of the assignment, the absence of guidance on key tasks, inadequate remuneration, working with strangers, and grappling with highly technical legalese (Goodman-Delahunty et al. 2008; Peter-Hagene, Salerno \& Phalen 2019). Criticisms of jury competence are perennial, and rely on dominant narratives, many of which have been exposed as myths (Bornstein \& Greene 2017). Unsurprisingly, avoidance of jury duty is a common response to a jury summons (Sams, Neal \& Brodsky 2013, p. 4). Jury reforms in this context are constant, and not necessarily evidence-based.

Most jury reform efforts centre on judicial directions, and are often ad hoc (Clough et al. 2019, p. 1). This focus derives from an outmoded model of jury information processing - a judicial myth that juries understand and adhere to every direction from the court, so all that has to be done is modify the directions to accomplish new judicial objectives. As more judges come to accept that juries struggle to understand and apply legal jury instructions, reliance on linguistic simplification to remedy the communication problem is diminishing. For example, during his tenure as Chair of the NSW Law Reform Commission, Justice Wood led initiatives to increase the participation of citizens on juries and supported a range of interventions to improve communications between courts and juries (Goodman-Delahunty 2015, p. 58). Contemporary reforms incorporate a paradigm shift that respectfully acknowledges jurors' active engagement as fact-finders:

It is true that, in modern times, it is seen as important that the jury be accorded respect, and not treated as passive recipients or mere observers of the trial process.

(Tootle v R (2017) 94 NSWLR 430 [59] (Simpson JA))

This chapter examines research on jury reforms and trial innovations related to procedural fairness to juries and to the accused. 


\subsubsection{Procedural fairness in jury trials}

A leading social psychological theory applied in the justice sector draws on the Group Value Relational Model (Tyler 1989) to support policies and practices that focus on interpersonal relational values. Procedural Justice Theory contends that the behaviour of an authority figure is evaluated in terms of what it communicates regarding the social relationship between the individual citizen and the authority. Thus, the manner in which disputes are handled has an important influence upon people's evaluations of their experiences in court and of the criminal justice process. Some research has explored ways in which procedural justice can be incorporated into courts. Notably, these findings

do not apply only to litigants or other members of the public who come to court (the 'clients' of the court system). They also apply to the people who work within the court system ... and the same principles that can be used to design efforts to deal with the public also apply to efforts to design effective approaches to dealing with the people working within the criminal justice system.

(Tyler 2008, p. 29)

Another important factor is the perceived legitimacy of the laws and confidence in the justice system - a factor that seems to be directly associated with perceived procedural justice (Murphy 2018; Murphy, Tyler \& Curtis 2009).

The four key principles or tenets of procedural justice are respect, trustworthiness, neutrality, and voice (Tyler 1989, 2008). We consider these four concepts in turn, both their direct effects on juries, and to a lesser extent, to the accused with an indirect effect on juries.

In its original formulation, respectful treatment refers to the treatment of citizens with professionalism and dignity. Respect could refer to the consideration the judge shows the jury: acknowledging their contribution, providing clear instructions, giving the jury comfort breaks, and giving them opportunities to ask questions when appropriate. Additionally, respect could refer to democratic practice in the jury room: civil discourse, taking turns to speak, and attempting to incorporate diverse perspectives into a common view. In this chapter, we focus on the respect shown to the accused by the way they are accommodated in court and the consequential effects on juries. A more general issue this raises is the way the design of court facilities incorporates principles affording dignity to different participants.

Trustworthiness refers to the public perception of courts' openness, sincerity, and motivation to serve the best interests of the jury and community. The notion of trustworthiness could draw attention to the integrity and credibility of judges in the eyes of jurors, but could also refer to how the public think about the jury system itself and particular verdicts.

Neutrality is the perceived absence of biased treatment. In one sense juries should be neutral. Clearly, jurors should not pre-judge a matter and should come 
with an open mind to the case-unlike early English juries where prior knowledge of the matter was precisely what was required. Jurors are expected, however, to bring common sense. Further, as members of a diverse community, jurors come with a range of expectations, preconceptions, and biases. Potentially this is an advantage, in that the jury deliberation can provide an opportunity for jurors to challenge each other and bring their different experiences of life to assess the credibility of witnesses and the accused to decide how much of their evidence to accept. However, this may sometimes be wishful thinking. Jurors may share stereotyped views about members of minority or disadvantaged populations; they may (often unconsciously) apply assumptions about how a mother should react to the loss of a child, how people of a particular ethnic group treat women, or how priests can be expected to behave with children.

Voice refers to citizens' sense of being heard and having their input valued (Goodman-Delahunty 2010, pp. 404-405). As such, voice is the one aspect of procedural justice that seems least relevant to the role of the jury. For the most part, jurors silently and passively observe the criminal trial (Dann \& Hans 2004, p. 12). They do not disagree openly with the judge, talk to the witnesses in the corridor, talk to fellow jurors as they listen to the evidence, or 'friend' the prosecutor or the defence lawyer on Facebook. Indeed, jurors who do any of these things could find themselves in trouble. When they sit on a jury trial, the normal forms of voice that jurors use in their everyday lives are closed to them. Yet voice is fundamental to jury deliberation, and to the oral process that is a public trial. What witnesses say on the stand constitutes the raw material for the jury to consider and evaluate in order to make their findings of fact. In doing so, the jury finally gets their chance to use their voice, as they review, assess, deliberate, and try to reach consensus. Yet it is a constrained voice. Common law juries almost never give reasons for their decision. Voice for the accused in a jury trial also takes an unusual form, namely the right to remain silent, a right that many counsels advise their clients to exercise. For the jury this may mean that they do not hear 'both' sides of a case; they hear mostly the prosecution evidence and have to decide if it reaches the standard prescribed by the court.

The four elements identified in the procedural justice literature shine light on some aspects of jury trials. We distinguish respectful treatment of jurors and the perceived legitimacy of jury trials in general from fairness to the accused. We deal with each of these in turn as we review contemporary jury interventions in the following sections. Chief among these are innovations to enhance the physical environment and quality of technology in courtrooms (Section 2.2); to entrust juries with evidence presumed to be prejudicial and supplement jury directions with fact-based question trails (Section 2.3); and to increase jury participation in the trial (Section 2.4). Finally, we discuss legitimacy of the jury and confidence in the jury system.

\subsection{Procedural justice through the physical environment}

An extensive body of research examines how juries make decisions. By contrast, relatively little research explores how jurors are influenced by elements of their environment, such as the design of the courtroom or jury room, the placement of 
the accused, or the technology used in court. Attention to these aspects of the jury experience centres on two procedural justice tenets, namely, respect and neutrality.

Several studies have documented the physical discomfort that many jurors experience in poorly designed, physically inadequate jury boxes, and cramped deliberation rooms with no spaces to relax or unwind (Goodman-Delahunty et al. 2008, p. 108). Australian and New Zealand judges reported that the poor courtroom acoustics made communication difficult (Clough et al. 2019, p. 54). In one Sydney courtroom, a large pillar blocks visual contact between witnesses and jurors, so the jury has to view the witness on a video screen. While some of the research uses experimental methods, it is more difficult to access realistic courtroom environments than psychology laboratories more commonly used to explore other jury-related issues.

\subsubsection{Jurors: respectful jury facilities}

\section{The courtroom}

The courtroom has not always been a safe and comfortable place for jurors. English courtrooms were typically cold, draughty, and, at least until the nineteenth century, rife with infectious diseases. Court officials and architects came to believe that a well-designed courtroom was essential to evoke the right emotional responses in jurors, a principle expressed in the nineteenth-century re-design of the Palais de Justice in Paris:

In a nondescript courtroom, cold and mean, the architecture cannot help the juror to comprehend the gravity of his role, the weight of the terrible responsibility that he assumes. In a room in which the forms, proportions and decorations are out of the ordinary, able to astonish and surprise, his emotions are different, he feels that he has been removed from his milieu to an exceptional, abnormal situation.

(Narjoux cited in Taylor 1993, p. 101)

The ideal courtroom was therefore conceptualised as one that took jurors out of their everyday lives to assume the 'terrible responsibility' of their office. As for forms, proportions and decorations being 'out of the ordinary', school children perform worse when visual stimulation in the environment is high, so jurors may be similarly distracted by overly ornate courtrooms (Barrett et al. 2015, p. 129).

Designing respectful jury spaces in the modern courtroom, more prosaically, focuses on providing comfortable spaces that allow jurors to concentrate on their task (Ingham \& Spencer 1977) describe similar aspects in medical waiting rooms). As the design standards for the Western Australian justice system specify:

Jurors should be extended the comfort and courtesies appropriate to people who must concentrate and remain alert for what can in some cases be for extended periods of time.

(Government of Western Australia 2017, p. 68) 
Other design features of the courtroom may reflect the level of respect with which the justice system treats the jury, and may potentially affect jurors' ability to listen attentively to the evidence and contribute to a more relaxed, or conversely stressed, jury. While there are few studies that document how more respectful spaces improve jury performance-specifically how listening more attentively is likely to render a more accurate verdict-we can draw tentative conclusions from research carried out with other groups in other workplaces. For example, in other workplaces, good lighting, thermal comfort, and an absence of noise has been found to contribute to increased comfort and less tired workers (Vischer 2007). We also know that students are more likely to keep 'on task' when they have full-spectrum lighting (Pulay 2015, p. 74). Attention to lighting may likewise be important for jurors' comfort and ability to attend to the trial. Another study has demonstrated that perceived privacy increases satisfaction with the work environment (Ruijter 2006, p. 7). For jurors, an innovation to address privacy could include modesty panels in front of the first row of jury seats.

\section{The jury room}

Special areas for juries to deliberate were not necessary for Greek or Roman juries, who voted immediately after hearing the evidence. Nor were they always available for English juries until the eighteenth century-jurors usually huddled together to reach their decision without retiring. But juries did not deliberate for long. Juries in seventeenth-century England typically heard between 12 and 20 cases in a day (Phillips \& Thomas 1986, p. 207). If they could not agree, it was standard practice until 1870 to lock them up overnight 'without meat, drink, fire and tobacco' (Phillips \& Thomas 1986, p. 210).

With longer trials and more evidence to sort through, jury rooms began to become more comfortable, and juror treatment more respectful. Jury facilities built since the 1990s in three Australian states were rated by jurors more favourably than those in older courthouses. Satisfaction with the comfort of the jury room ranged from a high of $73 \%$ for the 5 -year-old Victorian County Court in Melbourne to a low of $26 \%$ for the Downing Centre in Sydney, converted from a department store in 1985 (Goodman-Delahunty et al. 2008, p. 138). Features of jury rooms with considerable variation between older and newer courts included direct access to outdoor space (garden or balcony) and natural ventilation (access and quality) (Goodman-Delahunty et al. 2008, pp. 119-121). Architectural enhancements such as these have a measurable impact on juror satisfaction, and convey greater respect shown to jurors by the justice system.

The design of furniture in the jury room may impact the ability of individual jurors to have their say-to voice-during deliberation. The position of jurors at a rectangular jury table influences power dynamics and interactions among jurors, with the person seated at the head of the table most likely to be voted foreperson, and people seated at right angles more likely to interact with each other than with those either across the table or alongside (Sommer 1959, p. 401). 
A round or square table might produce more equal interactions (Sommer 1961, p. 108). To address some of these concerns, a report to the Western Australian Law Reform Commission recommended replacing rectangular with round tables for jury deliberation (Kennedy \& Tait 1999, p. 1050). Size constraints in many jury rooms made this impractical, so new jury rooms tend to provide an oval table for jury use. Whether this type of deliberation space gives more voice to less confident jurors or produces mutual respect is largely unknown.

\subsubsection{The accused: neutral spaces in the courtroom for the accused}

How the accused is accommodated in the courtroom can influence jury perceptions of the accused, and consequently the fairness of the trial process and outcome. This issue has generated much judicial and academic commentary and a small number of experimental studies. Key questions are i) how the accused can be granted a voice in the trial proceedings (generally described as instructing counsel), and (ii) whether the placement of the accused in the courtroom conveys respect for their human dignity, and is perceived as neutral rather than prejudicial. The jury is, in a sense, the critical test for each of these.

Nineteenth-century juries tended to see the accused in a designated area variously known as a box, a dock, or bench (Anklagebank or banc des accusés). In European courts, the accused spoke and was questioned from this position; in common law countries, the accused moved to a witness stand. The use of a dock was challenged in a 1914 Pennsylvania case on the grounds that placement of the accused in a dock undermined his right to consult his lawyer (Commonwealth v Boyd, $246 \mathrm{~Pa} 529,535$ (1914)) and thereby his right to voice. Any form of visible constraint was ruled unacceptable in 1970 by the US Supreme Court in Illinois $v$ Allen (397 US 337, 344 (1970)) for undermining the right to dignity. Meanwhile, in 2005 the US Supreme Court held that any mark of restraint, including a dock, undermined the presumption of innocence and could create prejudice in the minds of jurors (Deck v Missouri, 554 US 622, IIIA (2005)). Similar shifts away from the use of an enclosed area for the accused occurred in Germany, Ireland, and Scandinavian countries, while Australia, the UK, and most of Central and Eastern Europe moved towards greater use of security docks of some sort (Tait 2011, p. 468, 478-479). But what evidence is there that isolating the accused in this way may compromise jury neutrality and jeopardise the fairness of the trial for the accused?

Generally, we associate people with the environment in which they appear-the ecological contamination hypothesis (Werthman \& Piliavin 1967, p. 56), or the 'room with a cue' (Gosling et al. 2002, p. 387). Thus, confining accused persons within the courtroom may signal to the jury that they are dangerous. One field experimental study, using a terrorism scenario and mock jurors in a high-security counter-terrorism courtroom, revealed that the accused was about 1.8 times more likely to be convicted (and to appear 'dangerous') if he was seated in a dock, compared to being seated beside his lawyer at the bar table (Rossner et al. 2017). The dock provided a 'box with a cue' for the jury telling them that the accused 
was guilty. A subsequent mock jury study, using a dog-fighting scenario and a low-security courtroom, replicated this finding (Tait et al. 2017). If the accused person was seated in a dock in the courtroom, he was 1.7 times more likely to be convicted for that matter than when sitting alongside his lawyer in court, or in a remote location. These studies support the US Supreme Court's assertion that any form of visible constraint of the accused can be prejudicial.

Fairness for the accused may also potentially be threatened by another aspect of court design - the relative position of the two parties. A fundamental principle of an adversarial contest, such as a trial, is equality of arms. This includes whether either party is given a physical position in court that affords them a symbolic advantage. In older French courts, the Avocat général, the prosecutor, typically sits on a throne, in a red gown fringed with ermine, and, when standing, is the tallest person in the room. By contrast, the defence lawyer is located in the well of the court, usually dressed in black. The cue provided to the jury by this placement could be that the voice of the prosecutor counts more than the voice of the defence lawyer. Largely for this reason, newer French courts tend to place the two parties at the same level. Differences in common law courts are more subtle, but the lawyer whose table is closest to the jury might have an advantage by virtue of proximity.

\subsection{Procedural justice through the management of evidence and jury directions}

A series of innovations in jury trials centres on the trustworthiness of juries and their neutrality. These include procedural features such as management of the evidence to which juries are exposed, to avoid bias, and greater attention to the capacities and welfare of juries, reflected in jury instructions on the law, and the availability of counselling services for jurors.

\subsubsection{Exclusion of prejudicial information}

To ensure the right of the accused to a fair trial, a number of jury procedures have been implemented to avoid the risk of verdicts based on unfair prejudice. This includes the exclusion from a trial of relevant probative evidence. This is more critical in jury systems that follow the English model, with lay jurors deliberating on their own. In most mixed-panel jury systems where jurors and judges deliberate together, wider tolerance is given to evidence admitted during the trial, including evidence about prior convictions of the accused. Exclusion of such information may, however, demonstrate a lack of trust in the jury. In some cases, evidence that is withheld from the jury is available to the trial judge in a judge-alone trial, and the extent to which this evidence may be unfairly prejudicial is not empirically validated. For example, judges would typically not allow jurors to see beheading videos that the prosecution argues are relevant to a case, although the judge may view them themselves in a judge-only trial (Goodman-Delahunty 2017). 
Studies of real jurors in Australia and New Zealand indicate that jurors often believe that they do not get all the relevant evidence they need to arrive at a fair and impartial decision (Horan 2012; Young, Cameron \& Tinsley 1999), particularly in word-against-word cases. Juries are often frustrated by what they perceive as gaps in the trial evidence, and by the application of evidentiary rules that preclude courts and lawyers from placing all salient probative facts before them. For instance, evidence from multiple complainants about their experiences with the same defendant is often excluded to ensure that juries do not engage in impermissible reasoning that is unfairly prejudicial to the accused. This issue was investigated in a realistic live controlled jury simulation study using examples of institutional child sexual abuse by a repeat offender. Mock jurors attended either (a) a standard trial including one complainant; (b) a trial in which additional evidence about grooming behaviour and four uncharged acts of sexual abuse against the same complainant were provided; or (c) a trial in which additional evidence about four uncharged acts by the accused against two additional victims was presented (Goodman-Delahunty \& Martschuk 2020). The major finding was that juries exposed to evidence of additional sexual misconduct by the same perpetrator (tendency evidence) did not engage in unfairly prejudicial reasoning. Jury observations and content analyses of deliberations showed that exposure to evidence of prior offending by the accused did not cause juries to lower the standard of proof or render verdicts that were emotionally driven, illogical, based on accumulation of evidence, or confusion of charged and uncharged acts.

From a procedural justice standpoint, the admission of probative background evidence conveys trust in the jury and respect for their conscientiousness in avoiding bias. Withholding this information not only frustrates juries, but conveys disrespect by insinuating their verdicts are untrustworthy, prone to bias and unfair prejudice. Among the actions that jurors may engage in when they perceive gaps in the relevant information needed to reach a fair decision is to resort to social media to conduct extra-curial research, e.g. internet searches, to which we now turn.

\subsubsection{Jury directions probibiting internet research}

Typically, juries receive judicial directions that forbid internet research accompanied by information about the consequential criminal penalties. For example, section 68C of the Jury Act 1977 (NSW) prohibits a juror from seeking information about the accused or any matters relevant to the trial, and punishes violations with a sentence of up to two years in prison. Academics, legal practitioners, and judges (Sweeney 2011) have acknowledged that the traditional paradigm of judicial instructions with a threat of sanctions is premised on passive pre-internet jurors, but does not work reliably with contemporary active, information-seeking, internet-aware jurors.

Internationally, since access to this technology became widespread, the number of 'Google mistrials' burgeoned. In one Florida drug trial, 9 out of 12 jurors admitted conducting internet research on the case (Blackman \& Brickman 2011, p. 2). 
In high profile trials and in trials where information about the trial is posted on the internet, more jurors are prone to violate the judicial direction (HannafordAgor, Rottman \& Waters 2012, p. 3).

Research with US juries serving on 35 trials revealed that most jurors wanted to use the internet to conduct research to assist them in their jury duties because they were accustomed to using social media in this way on a daily basis (Hannaford-Agor, Rottman \& Waters 2012, p. 6). Approximately one-third of jurors misunderstand the scope of the judicial admonition regarding social media (Hannaford-Agor, Rottman \& Waters 2012, p. 6). This was often because 'Googling' was not regarded as an activity comprising 'research', but was perceived as something more informal, and an exercise of juror engagement or voice. Other jurors believed that using the internet to obtain general information was not prohibited because they understood the prohibited conduct to apply to searches for specific information pertaining to the parties and the particular case (Hannaford-Agor, Rottman \& Waters 2012, p. 6). For instance, many jurors did not recognise that use of the internet to check definitions of terms that were not explained by witnesses or legal counsel constitutes proscribed 'research' because they regard this as non-prejudicial, neutral extrinsic information, necessary to perform their duties.

Researchers have attributed juror non-compliance with judicial directions to several factors. Some emphasise that the judicial direction is counter-intuitive to contemporary jurors, who are accustomed to reliance on the internet (Waters \& Hannaford-Agor 2014, pp. 2735, 2737). Contemporary jurors rely extensively on the internet to inform their decision-making in other aspects of their lives, such as health care, finances, and education. From the individual juror's perspective, such research aims to produce a more trustworthy, well-informed verdict. From the point of view of public confidence in justice, however, it suggests that the integrity of the jury process and the authority of judges could be diminished.

An Australian field study explored what motivated jurors to engage in internet and other independent investigations. A total of $78 \mathrm{New}$ South Wales jurors who served on criminal trials in the period 2005-2006 and 2011 were interviewed. Results disclosed that it is the conscientious jurors who feel most compelled to conduct independent research to reach a fairer and well-informed decision (Hunter 2013, p. 37). A major case-related factor explaining jurors' compulsion to conduct research is incomplete or insufficient evidence. Jurors knowingly defy judicial directions to refrain from independent research because they perceive a higher duty to return a more robust and trustworthy verdict, and are more prone to do so when the evidence presented at trial seems incomplete (Horan 2012, pp. 166-167).

Courts responding to jury use of the internet should respect the need by jurors, especially conscientious jurors, for more information. Allowing juries to submit questions to the court or to witnesses is an innovation proposed to reduce independent juror investigations and internet use (Hoffmeister 2015, p. 994). This innovation (discussed below) increases jury participation in trials, reflects respect for and trust in juries, and increases their voice. 


\subsubsection{Aiding jury decision-making with questions}

After decades of research confirming that juries often struggle to understand and apply legal directions provided at the conclusion of a trial (Peter-Hagene, Salerno \& Phalen 2019, p. 353), a number of jurisdictions have experimented with an innovation that removes this burden from jurors and focuses on their fact-finding abilities. By embedding the law and relevant facts in a series of questions that are posed to juries, called a 'question trail' (Spivak, Ogloff \& Clough 2019, p. 443), the need to provide juries with lengthy instructions on legal definitions and principles is obviated. Among logistic advantages of this approach are that it could shorten deliberation times, thereby reducing demands on court space and resources. However, the primary objective is to encourage the jury to handle the evidence in a systematic way that will allow them to reach a fair decision. In other words, juries are trusted to understand what the evidence is and how it is relevant to the choice they have to make.

Nowadays, more judges are adopting fact-based directions (Clough et al. 2019, p. 50). For example, this approach is routine in New Zealand courts. Evidence about the benefits of this approach comes from a realistic trial simulation with 403 mock jurors who deliberated to a verdict using standard judicial directions or standard directions accompanied by a question trail (Goodman-Delahunty, Cossins \& Martschuk 2016, pp. 222-230). Results showed that question trail use increased the efficiency of jury decision-making and reduced deliberation time. Jurors who used the question trail reported significantly less cognitive effort to reach a unanimous verdict than those who did not. Content analyses of jury deliberations revealed that mock jurors given a question trail spent more time on discussion of the charges, judicial principles, and instructions than jurors given traditional jury directions.

Similarly, mock jurors reported expending less cognitive effort to evaluate the defence case when assisted by the question trail. Such effects are either logistical (less time taken), or provide psychological benefits for the jurors themselves (reduced cognitive load). Whether the decisions made are fairer to the accused is yet to be established. It is possible, for example, in matters where the jury may be considering nullification, where they consider the prosecution is over-zealous or the law is unjust, that a question trail may act as a constraint on their voice.

\subsubsection{Juror counselling}

Increasingly, courts acknowledge that jury participation may come with a cost, as the experience of jury service can cause some jurors significant stress and anxiety. This is due to a number of factors, including unfamiliarity with the task, the burden of isolation and secrecy, uncertainty, financial insecurity, the explicit or traumatic nature of the evidence (Goodman-Delahunty 2017, p. 91), conflicts with other jurors, and the gravity of consequences of a life-altering verdict.

The dominant jurisprudential concern has been the extent of discomfort while evidence is displayed, rather than the impact on a juror's subsequent wellbeing 
and decision-making, or the types of procedural measures to ensure psychological support for jurors, so that juror stress can be avoided or minimised. Surprisingly, a survey of judges in Australia and New Zealand revealed that not all courts inform jurors of the availability of juror counselling services, and that some judges were unaware of available services within their own courts (Clough et al. 2019, p. 55).

Favourable cues to the trustworthiness of authorities come from indications that their intentions are benevolent, caring, and sincere in trying to do what is best for the people with whom they are dealing (Murphy 2018). Contemporary courts are showing more genuine concern for the welfare of jurors, in line with the procedural tenet of trust. They are educating judges and juries to better recognise symptoms of psychological distress, informing them of available counselling services, and providing trial debriefing after a case closes to assist jurors in dealing with the aftermath of jury service (Report of the Standing Committee on Justice and Human Rights 2018, pp. 19-24). Arguably, these measures also reflect a more respectful treatment of juries and increase their satisfaction with jury duty (Miller \& Bornstein 2013, pp. 252, 254, 256).

\subsection{Procedural justice through increased jury participation}

Enabling jurors to participate more actively in a trial increases the procedural justice tenet of voice. Examples of trial procedures that expanded jurors' voice are notetaking and allowing jurors to submit questions to witnesses.

\subsubsection{Taking notes}

The role of juries as observant bystanders during a trial is largely passive. Nevertheless, there are some small shifts to increase jury participation during the trial. Allowing, or more strongly encouraging, jurors to take notes is one practice that has been adopted in many jurisdictions. This assists jurors to keep track of the evidence, particularly over a long trial, rather than relying on the necessarily selective summing up of counsel to remind them of the main lines of argument and points of evidence. In some older courtrooms on a hot afternoon, any manual activity, including notetaking, may help jurors to remain alert and awake. Notetaking can assist jurors to ask questions of witnesses. However, the main benefit of juror notetaking is the expectation that it will assist in deliberation. When jurors take notes, this makes it more likely that important evidence is discussed around the jury table. In addition, faulty memories of some jurors are corrected by reference to contemporaneous notes taken by others. Given that one of the claimed advantages of the jury system is the way the selection process may result in jurors with rather different backgrounds and views being able to challenge each other's prejudices, it is expected that they will similarly be able to correct and challenge each other's notes.

That at least is the theory. In practice, any improvement in the collective memory resulting from juror notetaking is 'modest' (Dann \& Hans 2004, p. 14), although jurors tend to believe the practice improves their recall and judges are 
strongly in favour of it. However, there are no reported downsides to the practice, such as lengthening the deliberation process or giving more weight in the jury room to the views of those who chose to take notes. Jurors who took notes were likely to recall more legally relevant facts (Hope, Eales \& Mirashi 2014, p. 325 ). Whether case outcomes are impacted by notetaking is unclear. In a recent study using a criminal vignette, whether mock jurors took notes made no difference to verdict, verdict certainty or verdict satisfaction (Thorley, Baxter \& Lorek 2016, p. 567). Perhaps civil verdicts may be more susceptible to the influence of notetaking. Mock jurors who took notes distinguished between the legal situations of plaintiffs better than those who did not (Foster, Horowitz \& Bourgeois 1994, p. 576). In another study, damage awards from mock juries who did not take notes were higher than those from their counterparts who did (Horowitz \& Bordens 2002, pp. 383-384).

There are several forms in which notes may be taken. Jurors are likely to take more complete notes if they are given organisational cues in the form of a structured notebook with headings than if they write their notes freestyle (Thorley, Baxter \& Lorek 2016, p. 568). When jurors structured their own notebooks in a systematic way, they had better recall than jurors who were less organised (Rosenhan, Eisner \& Robinson 1994, pp. 58-59). On the other hand, better notes do not necessarily translate into the ability to retrieve information subsequently (Thorley, Baxter \& Lorek 2016, p. 569). Retrieval of information may improve with the use of tablets rather than paper to take notes. With an evidence book on tablets, some jurisdictions allow jurors to add their own notes in digital form, avoiding the need for two different technologies. This has two important consequences, both of which have yet to be studied in detail. The first is that the notes may tag or highlight the evidence, providing not so much a summary as an interpretation or cue. Second, having an evidence book in digital form allows the original evidence to form the basis of jury deliberation, with the annotations providing speedy access to the relevant place in the evidence book. Juries tend to find information more quickly on iPads than paper evidence books (McDonald et al. 2015), and with the additional cues provided by annotations, this process may be hastened still further.

There are some questions about the efficacy of these studies. For example, the effectiveness of notetaking may be greater in real trials than those reported for mock juries. Most mock jury studies are necessarily limited in time, with the length of performance typically about 30 minutes, compared to the typical trial which would run for anywhere from three days to six months. It is easier to recall something that one saw 15 minutes ago than six months ago. Further, mock trial scenarios tend to be ordered and parsimonious, whereas real trials are often confusing and repetitive. With many short mock trials, the failure to obtain significant improvements in memory simply reflects the fact that most participants are already near the top of the range.

In terms of the four elements of procedural justice outlined above, notetaking is relevant to all. It facilitates a voice for jurors, making the opportunity to ask questions of witnesses less stressful (compared to relying solely on memory), as 
well as allowing less confident jurors a prop to use in deliberation. In a mixed jury system, having notes might balance the scales a little, giving lay jurors some written material to access during deliberation to counter the advantage given professional jurors who have read the written dossier. The very act of writing notes empowers the jurors to select the evidence they consider relevant and provide their own interpretation of what they hear rather than relying on the unmediated statements of counsel (or the judge). The opportunity to take notes is a small mark of the respect accorded to the jury by the court; it assumes the members of the jury are not just competent in oral communication, but literate in written communication as well. Jury neutrality may be enhanced if notetaking reduces errors or omissions when recalling the evidence in deliberations. However, while taking notes necessarily involves the selection of what is most relevant, jurors are more likely to write down what they hear as they hear it, allowing them to cross-check what others say later. In the jury room this prompted memory aid may contribute to greater weight being given to the evidence adduced in court, at the expense of retrospective hunches, prejudicial comments, or other statements that could violate neutrality.

\subsubsection{Asking questions}

Traditionally, courts dealt with questions from juries that arose in the course of their post-trial deliberations, often simply by advising the jury to reread the jury directions. Starting in the late 1990s, courts experimented by allowing jurors to submit questions during the trial at the conclusion of a witness examination, after the counsel's presentation of the evidence (Heuer \& Penrod 1994; Mott 2003). Among the noted benefits were that jurors were better informed, thus less prone to bias. An analysis of the frequency and type of questions asked by jurors in North American trials revealed that the mean number per trial was 16 questions, although juries posed twice as many questions in criminal than civil trials. The researcher observed that the questions were intended to enhance the jury role as neutral fact-finder (Mott 2003, p. 119), in line with the procedural justice tenet of neutrality. This innovation was also rated as more respectful of jurors, by regarding them as 'intelligent and contributing members of the justice system' (Mott 2003, p. 1120). Jurors' questions fell into three major categories, seeking clarification of (a) legal standards; (b) the parties' or witnesses' motives; and (c) evidence. A smaller proportion of questions were about legal procedures or the meaning of legal directions. Conversely, if jurors are discouraged from asking questions they may perceive themselves as bystanders and more passive participants in jury trials, which may increase their dissatisfaction with the justice process (Horan 2012).

\subsection{The legitimacy of the jury}

Perceived procedural justice shapes satisfaction with the justice process (Murphy 2018), because it increases the perceived legitimacy of the laws. The perceived legitimacy of the jury is reflected in confidence in the jury system by the public, jurors, and legal practitioners. 


\subsubsection{Confidence of jurors in justice}

One claimed benefit of the jury system, or more particularly participating in the system as a juror, is that it will increase citizen confidence in the justice process. Jurors will, it is claimed, see for themselves how the system works, and develop an enhanced respect for the rule of law. This increased awareness would not relate to one trial or one judge, but to the system as a whole. Perceived legitimacy of the justice process could translate into greater support for judges and courts, and less criticism of the system as a whole when citizens disagree with the outcome of one trial.

Overall, Australian jurors have a moderate degree of confidence in the criminal justice process, as shown in a large-scale study of Australian jury-eligible citizens (Goodman-Delahunty, Cossins \& Martschuk 2016) using the Pretrial Juror Attitude Questionnaire (Lecci \& Myers 2008). Compared to jurors in the United Kingdom (Furnham \& Alison 1994) or the United States (Chapdelaine \& Griffin 1997), Australians held more pro-prosecution attitudes (Goodman-Delahunty, Martschuk \& Cheung 2020). This is a measure of the trustworthiness of one element of the criminal justice process, but given the items used to measure it, is likely to diminish another key feature of the justice system-the presumption of innocence.

At the same time, jurors' exposure to and contact with the court may influence their confidence in the criminal justice process (Diamond 1993). Despite initial reluctance to serve on juries, at the completion of their service, most jurors express a high degree of satisfaction (Cutler \& Hughes 2001; Matthews, Hancock \& Briggs 2004). For instance, a survey of empanelled and non-empanelled jurors in three different states in Australia showed that more extensive participation in the court process (non-empanelled jurors versus empanelled jurors discharged before deliberation versus empanelled jurors who deliberated to a verdict) was associated with significantly higher satisfaction with their jury experience and increased confidence in the criminal justice process (O'Brien et al. 2008). These findings were replicated in an experimental simulation with jury-eligible participants, showing consensus that deliberation assisted them in reaching a verdict and increased their confidence in the verdict (Goodman-Delahunty, Cossins \& Martschuk 2016, pp. 236-237). One possible reason is that individual jurors in a diverse group may have relevant knowledge and experience to assist others with complex evidence or difficult legal constructs, leading to overall better performance of the group (Horan 2012). In addition, participation in deliberation, actively giving jurors from diverse backgrounds a voice in the justice process, increases citizens' commitment to the jury system and the legitimacy of the criminal justice process (Cornwell \& Hans 2011; Hans, Gastil \& Feller 2014).

\subsubsection{Confidence of legal professionals in the jury system}

A procedural justice analysis of juries cannot look simply at how juries themselves feel or respond. In terms of neutrality and trust, it also matters how juries are perceived by the public. Research on confidence in juries within the criminal 
justice process has shown that legal professionals who work most closely with juries have higher confidence in their abilities than those who do not. Justice Wood, who served as Chief Judge at Common Law in New South Wales, Australia, for eight years, remarked on how this experience, during which he was deeply engaged with juries in the most serious criminal cases, left him with strong confidence in the jury system as opposed to judge-alone trials (GoodmanDelahunty 2015 , p. 58). For these reasons, he opposed the weakening of or abolition of juries.

We investigated the extent to which legal professionals (prosecutors, criminal defence lawyers, judges, and jury administrators) endorsed jury trials using a sample of key stakeholders in the criminal justice system in three Australian states (Goodman-Delahunty et al. 2008). These legal professionals expressed significantly greater confidence in juries $(84 \%)$ than judges $(73 \%)$. All were asked whether they personally would choose a jury or a judge-alone trial, first, if they were the victim of a crime, and second if they were the accused. Results revealed a preference for trial by jury in both roles, but stronger if the participant were the accused. This degree of support for juries as an institution indicates that legal professionals see juries as legitimate. Since they are the group that works in close contact with juries, this provides some assurance that the jury is likely to survive, at least in common law countries.

\subsection{Conclusion}

This review has examined different aspects of procedural fairness in jury trials, using the four-fold-category developed by Tyler. Increased respect for jurors themselves has taken the form of better accommodation. Jury neutrality has been enhanced by the placement of the accused in court. Trust in the jury has been augmented by reforms more sensitive to the capacity and conscientiousness of juries as fact-finders, such as doctrines on the exclusion of prejudicial material, the management of internet research by jurors, uses of question trails to guide jury deliberations, and counselling services for distressed jurors. Greater voice for juries is demonstrated by increased opportunities for trial participation, such as the chance to take notes and ask questions. On the other hand, some changes have compromised jury neutrality. In countries such as the UK, Australia, and France, caging the accused in court runs the risk of prejudicing the jury against the accused.

Overall, this review suggests that enhanced relational contact between courts and juries yields increases in jurors' positive civic attitudes, willingness to serve, as well as satisfaction with the justice process. Increases in jury participation have enhanced the legitimacy of the criminal justice process. The support of legal professionals for the jury shows confidence in the jury system. The findings support the view that improved relational engagement in the criminal justice system through managerial practices and innovations that apply procedural justice tenets is critical to the effectiveness, legitimacy, and retention of the petit jury. 


\section{References}

Barrett, P, Davies, F, Zhang, Y \& Barrett, L 2015, 'The impact of classroom design on pupils' learning: final results of a holistic, multi-level analysis', Building and Environment, vol. 89, pp. 118-133.

Blackman, J \& Brickman, E 2011, 'Let's talk: addressing the challenges of internetera jurors', The Jury Expert, vol. 25, no. 2, pp. 1-11.

Bornstein, BH \& Greene, E 2017, The jury under fire: myth, controversy, and reform, Oxford University Press, New York.

Chapdelaine, A \& Griffin, SF 1997, 'Beliefs of guilt and recommended sentence as a function of juror bias in the OJ Simpson trial', Journal of Social Issues, vol. 53, no. 3 , pp. 477-485.

Clough, J, Spivak, B, Ogloff, JRP, Ruffles, J, Goodman-Delahunty, J \& Young, W 2019, The jury project 10 years on: practices of Australian and New Zealand judges, Australasian Institute of Judicial Administration, Melbourne, VIC.

Cornwell, E \& Hans, V 2011, 'Representation through participation: a multilevel analysis of jury deliberations', Law and Society Review, vol. 45, no. 3, pp. 667-698.

Cutler, BL \& Hughes, DM 2001, 'Judging jury service: results of the North Carolina administrative office of the courts juror survey', Behavioural Sciences and the Law, vol. 19, no. 2, pp. 305-320.

Dann, BM \& Hans, VP 2004, 'Recent evaluative research on jury trial innovations', Court Review, vol. 41, no. 1, pp. 12-19.

Diamond, SS 1993, 'What jurors think: expectations and reactions of citizens who serve as jurors', in RE Litan (ed.), Verdict: assessing the civil jury system, Brookings Institute, Washington, DC, pp. 282-305.

FosterLee, L, Horowitz, IA \& Bourgeois, M 1994, 'Effects of notetaking on verdicts and evidence processing in a civil trial', Law and Human Behavior, vol. 18, no. 5, pp. 567-578.

Furnham, A \& Alison, L 1994, 'Theories of crime, attitudes to punishment and juror bias amongst police, offenders and the general public', Personality and Individual Differences, vol. 17, no. 1, pp. 35-48.

Goodman-Delahunty, J 2010, 'Four ingredients: new recipes for procedural justice in Australian policing', Policing: A Journal of Policing and Practice, vol. 4, no. 4, pp. 403-410.

Goodman-Delahunty, J 2015, 'The Honourable James R Wood AO QC: New South Wales Supreme Court judge', in D Lowe and DK Das (eds), Trends in the judiciary: interviews with judges across the globe (vol. 2), CRC Press, New York, pp. 57-76.

Goodman-Delahunty, J 2017, 'Assessing unfair prejudice from extremist images in terrorism trials', in D Tait \& J Goodman-Delahunty (eds), Juries, science and popular culture in the age of terror, Palgrave MacMillan, London, pp. 87-121.

Goodman-Delahunty, J, Brewer, N, Clough, J, Horan, J, Ogloff, JRP, Tait, D \& Pratley, J 2008, Practices, policies and procedures that influence juror satisfaction in Australia, Research and public policy series report no. 87, Australian Institute of Criminology Research and Public Policy Series, Canberra, ACT.

Goodman-Delahunty, J, Cossins, A \& Martschuk, N 2016, Jury reasoning in joint and separate trials of institutional child sexual abuse: an empirical study, Royal Commission into Institutional Responses to Child Sexual Abuse report, Sydney. 
Goodman-Delahunty, J \& Martschuk, N 2020, 'Mock jury and juror responses to uncharged acts of sexual misconduct: advances in the assessment of unfair prejudice', Zeitschrift für Psychologie, vol. 228, pp. 199-209.

Goodman-Delahunty, J, Martschuk, N \& Cheung, S 2020, 'Juror bias, demographic correlates, and verdict: findings from a large Australian sample', Unpublished manuscript.

Gosling, SD, Ko, SJ, Mannarelli, T \&Morris, ME 2002, 'A room with a cue: personality judgments based on offices and bedrooms', Journal of Personality and Social Psychology, vol. 82, no. 3, pp. 379-398.

Government of Western Australia 2017, 'Department of justice, design brief for courthouses in Western Australia', viewed 3 October 2019. Available at https:// courts.justice.wa.gov.au/_files/courts_design_brief.pdf

Hannaford-Agor, P, Rottman, D \& Waters, NL 2012, Juror and jury use of new media: a baseline exploration, National Center for State Courts, Williamsburg, VA.

Hans, VP, Gastil, J \& Feller, T 2014, 'Deliberative democracy and the American civil jury', Journal of Empirical Legal Studies, vol. 11, no. 4, pp. 697-717.

Heuer, L \& Penrod, S 1994, 'Juror notetaking and question asking during trials: a national field experiment', Law \& Human Behavior, vol. 18, pp. 121-150.

Hoffmeister, T 2015, 'Preventing juror misconduct in a digital world', Chicago-Kent Law Review, vol. 90, no. 3, pp. 981-1000.

Hope, L, Eales, N \& Mirashi, A 2014, 'Assisting jurors: promoting recall of trial information through the use of a trial ordered notebook', Legal and Criminological Psychology, vol. 9, no. 2, pp. 316-331.

Horan, J 2012, Juries in the twenty first century, Federation Press, Sydney.

Horowitz, IA \& Bordens, KS 2002, 'The effects of jury size, evidence complexity, and note taking on jury process and performance in a civil trial', Journal of Applied Psychology, vol. 87, no. 1, pp. 121-130.

Hunter, J 2013, Jurors' notions of justice: an empirical study of motivations to investigate \& obedience to judicial directions, UNSW Jury Study, Law \& Justice Foundation, Sydney, NSW.

Ingham, B \& Spencer, C 1997, 'Do comfortable chairs and soft lights in the waiting area really help reduce anxiety and improve the practice's image?', Health Psychology Update, vol. 28, pp. 17-20.

Kennedy, L \& Tait, D 1999, Court perspectives: architecture, psychology and Western Australian law reform, Western Australian Law Reform Commission, Perth, WA.

Lecci, L \& Myers, B 2008, 'Individual differences in attitudes relevant to juror decision making: development and validation of the pre-trial juror attitude questionnaire (PJAQ)', Journal of Applied Social Psychology, vol. 38, no. 8, pp. 2010-2238.

Matthews, R, Hancock, L \& Briggs, D 2004, Juror's perceptions, understanding, confidence and satisfaction in the jury system: a study of six courts, Home Office online report 05/04, Home Office, London.

McDonald, LW, Tait, D, Gelb, K, Rossner, M \& McKimmie, BM 2015, 'Digital evidence in the jury room: the impact of mobile technology on the jury', Current Issues in Criminal Justice, vol. 27, no. 2, pp. 179-194.

Miller, MK \& Bornstein, BH 2013, 'The experience of jurors: reducing stress and enhancing satisfaction', in MK Miller and BH Bornstein (eds), Stress, trauma, and wellbeing in the legal system, Oxford University Press, New York, pp. 247-267.

Mott, NL 2003, "The current debate on juror questions: "To ask or not to ask, that is the question", Chicago-Kent Law Review, vol. 78, pp. 1099-1125. 
Murphy, K 2018, 'Procedural justice, legitimacy, and policing', in G Bruinsma \& D Weisburd (eds), Encyclopedia of criminology and criminal justice, Springer, New York, pp. 4024-4034.

Murphy, K, Tyler, TR, and Curtis, A 2009, 'Does procedural justice help authorities when people question the underlying legitimacy of the law?', Regulations of Governance, vol. 3, no. 1, pp. 1-26.

O’Brien, K, Goodman-Delahunty, J, Clough, J \& Pratley, J 2008, 'Factors affecting juror satisfaction and confidence in New South Wales, Victoria and South Australia', Trends and Issues in Crime and Criminal Justice no. 354, Australian Institute of Criminology, Canberra, ACT.

Peter-Hagene, LC, Salerno, JM \& Phalen, H 2019, 'Jury decision making', in N Brewer and AB Douglass (eds), Psychological science and the Law, The Guilford Press, New York, pp. 395-416.

Phillips, JA \& Thomas, C 1986, 'Jurors v. judges in later Stuart England: the Penn/ Mead trial and Bushell's case', Law \& Inequality, vol. 4, no. 1, pp. 189-229.

Pulay, AS 2015, 'The impact of the correlated color temperature of fluorescent lighting and its influence on student on-task behavior in an elementary school classroom', PhD thesis, Oregon State University, Oregon.

Rosenhan, DL, Eisner, SL \& Robinson, RJ 1994, 'Notetaking can aid juror recall', Law and Human Behavior, vol. 18, no. 1, pp. 53-61.

Rossner, M, Tait, D, McKimmie, B \& Sarre, R 2017, 'The dock on trial: courtroom design and the presumption of innocence', Journal of Law and Society, vol. 44, no. 3, pp. 317-344.

Ruijter, RTM 2006, 'The effect of open-plan office designs on employees: a study on hair cortisol, functional', Master's thesis, Vrije Universiteit Amsterdam, Amsterdam.

Sams, D, Neal, T \& Brodsky, S 2013, 'Avoiding jury duty: psychological and legal perspectives', The Jury Expert, vol. 25, no. 1, pp. 4-8.

Sommer, R 1959, 'Studies in personal space', Sociometry, vol. 22, no. 3, pp. 247-260.

Sommer, R 1961, 'Leadership and group geography', Sociometry, vol. 24, no. 1, pp. 99-110.

Spivak, B, Ogloff, JRP and Clough, J 2019, 'Asking the right questions: examining the efficacy of question trails as a method of improving lay comprehension and application of legal concepts', Psychiatry, Psychology and Law, vol. 26, no. 3, pp. 441-456.

Sweeney, DM 2011, 'Worlds collide: the digital native enters the jury box', Reynolds Courts \& Media Law Journal, vol. 1, no. 2, pp. 121-146.

Tait, D 2011, 'Glass cages in the dock?: presenting the defendant to the jury', ChicagoKent Law Review, vol. 86, no. 2, pp. 467-495.

Tait, D, McKimmie, B, Sarre, R, Jones, D, McDonald, LW \& Gelb, K 2017, 'Towards a distributed courtroom', Research report, The Court of the Future Network, viewed 3 November 2019, https://courtofthefuture.org/publications/towardsdistributed-courtroom/

Taylor, KF 1993, In the theater of criminal justice: the Palais de Justice in second empire Paris, Princeton University Press, Princeton, NJ.

The Standing Committee on Justice and Human Rights 2018, Improving support for jurors in Canada, House of Commons, Quebec.

Thorley, C, Baxter, RE \& Lorek, J 2016, 'The impact of note taking style and note availability at retrieval on mock jurors' recall and recognition of trial information', Memory, vol. 24, no. 4, pp. 560-574. 


\section{Jane Goodman-Delahunty et al.}

Tyler, TR 1989, 'The psychology of procedural justice: a test of the group-value model', Journal of Personality and Social Psychology, vol. 57, no. 5, pp. 830-838

Tyler, TR 2008, 'Procedural justice and the courts', Court Review, vol. 44, no. 1, pp. 26-31.

Vischer, JC 2007, 'The effects of the physical environment on job performance: towards a theoretical model of workspace stress', Stress and Health, vol. 23, no. 3, pp. 175-184.

Waters, NL \& Hannaford-Agor, P 2014, 'Jury impartiality in the modern era', in G Bruinsma \& D Weisburd (eds), Encyclopedia of criminology and criminal justice, Springer, New York, pp. 2735-2745.

Werthman, C \& Piliavin, I 1967, 'Gang members and the police', in D Bordua (ed.), The police: six sociological essays, Wiley, New York, pp. 56-98.

Young, W, Cameron, N \& Tinsley, Y 1999, 'Juries in criminal trials, part two-a summary of research findings', New Zealand Law Commission, vol. 2, 26. 